\title{
Laser Treatment of Cp-Ti \& Ti-Ni Alloy Coated with Hydroxyapatite/ Silver Nanoparticles for Biomedical Applications
}

\section{Christen Tharwat ${ }^{1 *}$, E Girgis ${ }^{1}$, YA Badr ${ }^{2}, K_{\text {KM Ibrahim }}^{3}$, Shireen K Assem ${ }^{4}$, and Nour Sh El- Gendy}

\author{
${ }^{1}$ Solid State Physics Department, National Research Centre, Giza, Egypt \\ ${ }^{2}$ laser interaction with matter department, NILES, Cairo University Giza, Egypt \\ ${ }^{3} \mathrm{CMRDI}$, Helwan, Cairo, Egypt \\ ${ }^{4}$ Agricultural Genetic Engineering Research Institute (AGERI), Agriculture Research Center, Giza, Egypt \\ ${ }^{5}$ Egyptian Petroleum Research Institute, Nasr City, Cairo, Egypt
}

\begin{abstract}
In this investigation, the biocompatibility of alloying elements for $\mathrm{Cp}-\mathrm{Ti}$, and Ti-Ni titanium alloys was tested in order to estimate their suitability for biomaterial components. As this alloys used as orthopedic and dental implants. $\mathrm{Cp}$-Ti was tested as reference material. The investigation included the mechanical properties as corrosion and microhardness. The susceptibility of bacteria to the Ag-HA surface was also evaluated by assessing the inhibition of luminescence of Escherichia coli, pseudomonas aeruginosa, bacillus cereus, and micrococcus luteus bacteria. Our investigation suggested that silver-coated titanium implants could be a potential solution for the prevention implant-associated deep bone infections in orthopedics.
\end{abstract}

\section{Keywords}

Nd:YAG, Ag-HA Nps., Biomaterials, Ti implants

\section{Introduction}

Since the population ratio of the aged people is rapidly growing, the number of the aged people needing replacing failed tissue with artificial instruments made of biomaterials is increasing. In the aged society, demand for healthcare goods such as wheel chairs, artificial limbs and legs, etc. are also increasing [1,2]. Also bone fracture induces a chain of cellular and molecular events at the fractured site. Surgery is often needed for proper bone healing [3]. At present, the most widely used clinical therapies for bone replacement and regeneration employ autologous and allogeneic bone grafts. Autologous or autografts are implants contain living elements for bone growth from the patient's own bone, usually harvested from their palate, hip, chin, or pelvic crest, there's no risk of rejection it, requires a second surgery but there's not recommended for patients with low bone density. On the other hand allografts or allogeneic are human bone, usually harvested from cadavers, there's a risk of morbidity and mortality due to poorly screened sources. Another type of grafts known as xenograft is a bone or other tissue from animals, usually bovine or porcine, it must be manufactured in a specific manner to ensure sterility and biocompatibility, there are some examples include: Bio Oss by Osteohealth, and PepGen15 by Dentsply [4].
Based on the mechanical properties such as corrosion resistance, microhardness, and biocompatibility, metals and alloys which are suitable for orthopedic and maxillofacial surgery can be divided into four groups: 1) Stainless steels (e. g. DIN/ISO 5832-1 or AISI 316L), 2) Co-Cr alloys (cast DIN/ISO 5832-4 or wrought DIN/ ISO 5832-6), 3) Ta alloys, 4) Magnesium and its alloys, 5) Cp-Ti (commercially pure Ti, DIN/ISO5832-2) or Ti alloys such as Ti6Al4V (DIN/ISO 5832-3) [5].

Titanium alloy is capable of osteointegration with bone [6].Further, titanium is able to form a calcium phosphate layer on its surface [7]. Moreover, titanium forms a stable titanium oxide layer on its surface [8]. This advantage is responsible for the good biocompatibility of titanium alloy. Particles of titanium implants consist mostly of insoluble titanium oxides. They result from the passivation layer of the implant. If the implant layer is damaged for some reason, the layer is immediately reoxidised. This property protects the alloy and prevents the formation of chemical compounds other than oxides [9]. Although their excellent corrosion resistance and mechanical properties, titanium metal alloys have poor osteoinductive properties, fortunately it has been resolved recently by coating the metal with a layer of bio-ceramic, especially hydroxyapatite $\left[\left(\mathrm{Ca}_{10}\left(\mathrm{PO}_{4}\right)_{6}(\mathrm{OH})_{2}\right.\right.$, or

*Corresponding author: Christen Tharwat, PhD, Solid State Physics Department, National Research Centre, Dokki, Giza, Egypt, Tel: +202-01221487884, Fax: 12622, E-mail: christen.tharwat@gmail.com

Received: March 16, 2016: Accepted: August 08, 2016: Published: August 11, 2016

Copyright: $\odot 2016$ Tharwat C, et al. This is an open-access article distributed under the terms of the Creative Commons Attribution License, which permits unrestricted use, distribution, and reproduction in any medium, provided the original author and source are credited. 
$\mathrm{HA}$, which is the major inorganic component of the natural bone and able to accelerate bone growth onto the surface of implant during the early stages after implantation [10].

HA is a bioactive ceramic material with high biocompatibility and osseo conductivity which is the main components of human being bones and teeth. HA has the advantage that it inherits some properties of the human bones such as composition and structure. Properties of HA have found useful application for low-load bearings porous implants and coatings of metallic implants.

Silver nanoparticles (Ag NPs) are of great interest in their excellent electrical conductivities, optical properties, oxidative catalysis, antibacterial effects, etc. The antibacterial activities of silver particles have been noticed since ancient times. Silver ions and silver based compounds are highly toxic to microorganisms, showing strong biocidal effects on as many as 12 species of bacteria including Escherichia coli [11].

\section{Experimental Work}

\section{Materials}

Silver Nitrate (Sigma-Aldrich, 99.8\%), Sodium Borohydride LR (Alpha, 97\%), Sodium Metasilicate powder EP (Alpha, 99\%), Tricalcium Phosphate GRG (WINLAB, 90\%), Trizma Base, Primary Standard \& buffer (Sigma-Aldrich, 99.9\%), Sodium Sulphate anhydrous A.R (WINLAB, 99.5\%), Potassium Chloride A.R (Alpha, 99.99\%), Di-Ammonium Hydrogen Orthophosphate A.R (WINLAB, 98.0\%), Calcium Chloride dried (Oxford 95\%), Magnesium Chloride Hexahydrate A.R (WINLAB, 98\%), Sodium Hydrogen Carbonate A.R (WINLAB, 99.5\%), Sodium Chloride Extra pure (s.d.Fine-chem Ltd., 99.5\%), HCL acid grade ACs, ISO (Scharlau, 37\%), Ethyl alcohol (Laboratory chemicals, 96\%).

\section{Synthesis of CP-Ti alloys}

Titanium specimens preparation was based on Kh.M. Ibrahim, et al. method by melting in a vacuum induction skull melting furnace. This was repeated twice to get homogenous materials. Investment casting technique was used to prepare commercially pure titanium bars with diameters and lengths of 30 and $300 \mathrm{~mm}$, respectively. An Aluminum die was first prepared to form the wax pattern and then a ceramic mold was built on. The ceramic mold was heated to $900^{\circ} \mathrm{C}$ using a mold heater inside the induction furnace. In order to investigate the influence of ceramic mold on the structure of the cast $\mathrm{cp}-\mathrm{Ti}$ alloy, the specimens were sectioned longitudinally and photographed using stereo-microscopy. These bars were preconditioned by removing $2.2 \mathrm{~mm}$ from the surface through turning to get rid of the hard a-layer and to smooth the surface [12].

\section{Synthesis of Ti-Ni alloys}

Based on Kh.M. Ibrahim, et al. technique which is Conventional tungsten arc melting under vacuum the $\mathrm{Ti}-\mathrm{Ni}$ shape memory alloy was prepared. The composition of these alloys are Ti51-Ni49, (at. \%). The alloys were cast as a disc form with $40 \mathrm{~mm}$ diameter and $10 \mathrm{~mm}$ thickness. Each disc was cut into four equal pieces for metallurgical investigations. A quantitative chemical analysis of these alloys was performed by using electron probe micro-analyzer equipped with a wavelength dispersive X-ray spectrometer analysis system. The microstructure of the investigated shape memory alloys were studied by using scanning electron microscope (SEM) [13].

\section{Pre-treatment of Ti specimens}

The materials used in the experiment are $\mathrm{Ti}-\mathrm{Ni}$ (with a nominal composition of Ti51 and Ni49), a commercial pure CP-Ti. CP-Ti, Ti$\mathrm{Ni}$ specimens were provided from The Central Metallurgical Research and Development Institute - CMRDI. Specimens were cut from the plate, to a diameter of $2.8 \mathrm{~cm}, 2.2 \mathrm{~cm}$ respectively using a wire cutting device, and then ground on emery papers up to 2500 grit, washed in
Table 1: The Nd:YAG laser treatment parameters.

\begin{tabular}{|l|l|}
\hline Parameters & Nd:YAG laser \\
\hline Wavelength & $532 \mathrm{~nm}, 1064 \mathrm{~nm}$ \\
\hline Power per area & $5 \mathrm{watt} / \mathrm{cm}^{2}$ \\
\hline Energy & $2 \mathrm{~mJ}$ \\
\hline Beam diameter & $10 \mathrm{~mm}$ \\
\hline Repetition Rate & $10 \mathrm{HZ}$ \\
\hline Pulse Duration & $7 \mathrm{~ns}$ \\
\hline Time of irradiation & 1 minute \\
\hline
\end{tabular}

Table 2: The ions concentrations of the simulated body fluid.

\begin{tabular}{|l|l|l|}
\hline No. & Reagent & Quantity \\
\hline 1 & $\mathrm{NaCl}$ & $7.996 \mathrm{gm}$ \\
\hline 2 & $\mathrm{NaHCO}$ & $0.350 \mathrm{gm}$ \\
\hline 3 & $\mathrm{KCl}$ & $0.224 \mathrm{gm}$ \\
\hline 4 & $\left(\mathrm{NH}_{2}\right)_{2} \mathrm{HPO}_{4} \cdot 3 \mathrm{H}_{2} \mathrm{O}$ & $0.228 \mathrm{gm}$ \\
\hline 5 & $\mathrm{MgCl}_{2} \cdot 6 \mathrm{H}_{2} \mathrm{O}$ & $0.305 \mathrm{gm}$ \\
\hline 6 & $1 \mathrm{M}-\mathrm{HCl}$ & $40 \mathrm{~mL}$ \\
\hline 7 & $(\mathrm{About} 90 \%$ of total amount of $\mathrm{HCl}$ to be added $)$ \\
\hline 8 & $\mathrm{CaCl}_{2}$ & $0.278 \mathrm{gm}$ \\
\hline 9 & $\mathrm{Na}_{2} \mathrm{SO}_{4}$ & $0.071 \mathrm{gm}$ \\
\hline 10 & $\left(\mathrm{CH}_{2} \mathrm{OH}\right)_{3} \mathrm{CNH}_{2}$ & $6.057 \mathrm{gm}$ \\
\hline
\end{tabular}

acetone. Finally, the specimens were washed with distilled water and dried in air.

\section{Laser processing}

Nd:YAG (Nano second laser Continuum laser, PRII 8000, Electro- optics, Inc., Wyandotte, MI, USA) was used in this work. The Nd:YAG laser emitted a beam at $532 \mathrm{~nm}$ and $1064 \mathrm{~nm}$ and was operated in the pulsed mode. Laser beam was focused by a lens, its focal length $10 \mathrm{~cm}$, the target at 1.3 meter distance from the lens to expand laser beam on the target. The Nd:YAG laser treatment parameters used are presented in table 1.

\section{Preparation of HA/Ag nanoparticle coatings using SBF}

The reagent-grade chemicals in the table below were used in preparing Tris-HCl-buffered SBF solutions of $27 \mathrm{mM} \mathrm{HCO} 3$ in distilled water [14,15]. The SBF (simulated body fluid) solution resembled to a Tris- $\mathrm{HCl}$ buffered (at $\mathrm{pH} 7.4$ and $37^{\circ} \mathrm{C}$ ), the ions concentrations of SBF are shown in the table 2. The preparation of HA/Ag NPs. based on Sadjadi, et al. method with some modifications to fit the propose of the thesis.

where $\mathrm{Ca}_{3}\left(\mathrm{PO}_{4}\right)_{2}(14.01 \mathrm{~g})$ were first dissolved in synthetic body fluid SBF solution $(50 \mathrm{~mL})$, contained in separate beaker. Then $\mathrm{Na}_{2} \mathrm{SiO}_{3}$ (1 gm @ $9.195 \mathrm{~mL}$ ) was added drop wise to the above calcium phosphate suspension and stirred at $37^{\circ} \mathrm{C}$ for $1 \mathrm{~h}$. The solutions left for 1 day at room temperature without stirring. Thus formed and aged 'seeds' were removed from mother liquors by filtration and washed with distilled water. The filtered product was dried at $80^{\circ} \mathrm{C}$ in an electrical air oven. The dried result was individually heated up to $1000^{\circ} \mathrm{C}$ in a muffle furnace and were stored for $2 \mathrm{~h}$ at this temperature and then placed in air for cooling to ambient temperature. Then $1.0 \mathrm{~g}$ calcium hydroxyapatite product was dissolved in $6 \mathrm{~mL}$ distilled water and then, added $6 \mathrm{~mL} \mathrm{AgNO}_{3}(0.15 \mathrm{gm})$ to this mixture. After $1 \mathrm{~h}$ mixing in room temperature the color of mixture was changed from white to yellow. Then $200 \mathrm{~mL}$ sodium borohydride $(0.454 \mathrm{gm})$ was added to this mixture and rapidly filtered. The suspension was filtered and washed with distilled water and dried at room temperature. The result green dark product was designated as calcium hydroxyapatite with silver nanoparticles.

\section{Electrophoresis deposition of HA/Ag on Ti specimens}

First the electrodes and the specimens were washed with acetone and distilled water and then dried. The deposition was carried out at room temperature in $250 \mathrm{ml}$ beaker ( $2 \mathrm{gm} \mathrm{HA} / \mathrm{Ag}$ NPs. was added to 


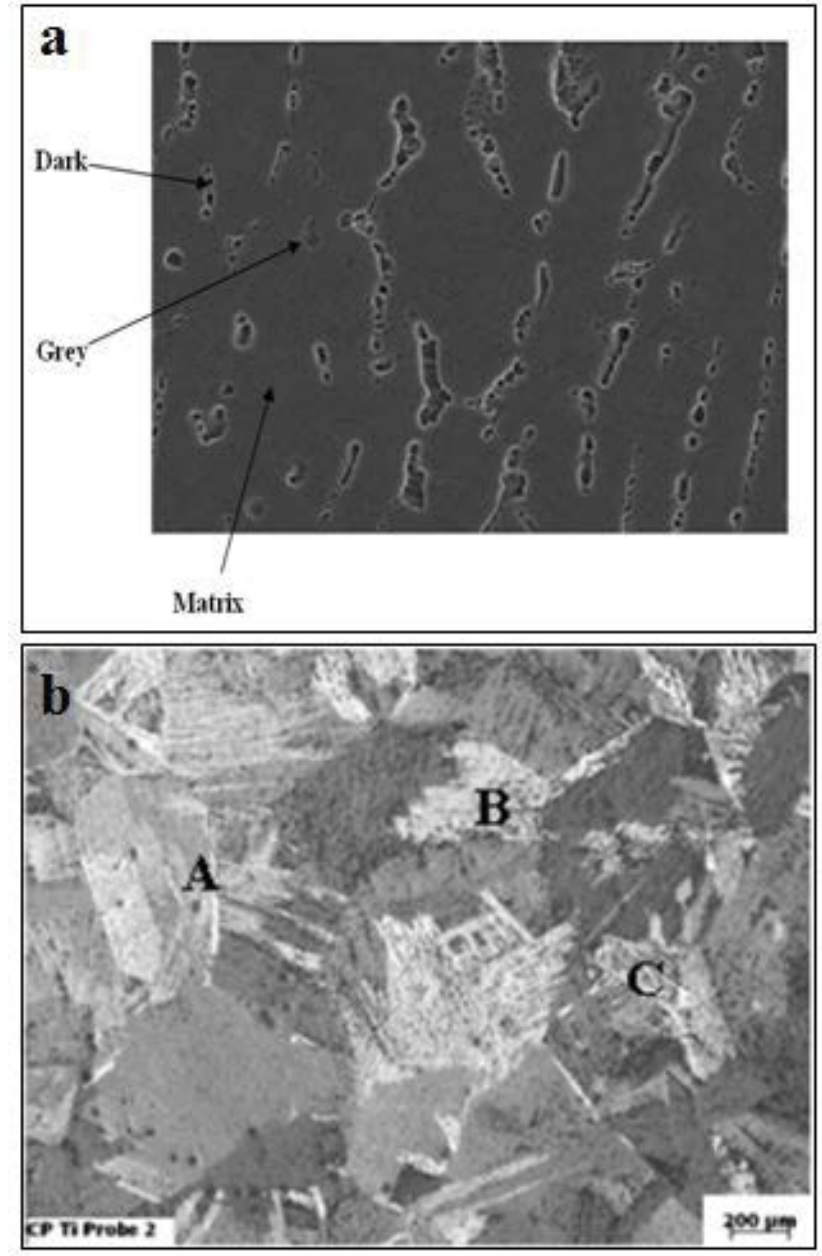

Figure 1: Microstructure of (a) Ti51 Ni49 alloy; and (b) Cp-Ti alloy.

$150 \mathrm{~mL}$ ethanol). The solution was stirred using a magnetic stirrer. A graphite rod (length $=6.5 \mathrm{~cm}$, Diameter $=0.7 \mathrm{~cm}$ ) was used as an anode and the sample was used at cathode. The distance between the electrodes was $2 \mathrm{~cm}$. For deposition of HA/Ag, voltage was $30 \mathrm{~V}$, current was $0.01 \mathrm{~A}$ for time of 20 minutes.

\section{In vitro performance}

Immersion test: The immersion test was carried out in SBF based on Shaokang Guan method with some modifications to fit the thesis propose [16]. The $\mathrm{pH}$ of SBF was adjusted with $\mathrm{HCl}$ and $\mathrm{NaOH}$, and the temperature was kept at $37^{\circ} \mathrm{C}$. The immersion solution was carried over $72 \mathrm{~h}$. The sample weight was measured before and after the immersion test. The corrosion rate was calculated by following equation (1.1), Where, Wo: original weight; W1: weight after immersion; S: original surface area exposed to the test solution; t: immersion time.

$$
\mathrm{CR}=\left(\mathrm{W}_{0}-\mathrm{W}_{1}\right) /(\mathrm{St})
$$

Antimicrobial activity testing: Antimicrobial activity of the powder specimens was tested against both Gram-positive (micrococcus luteus and bacillus cereus) and Gram-negative (pseudomonas aeruginosa and E.coli) bacteria. The bacteria strains were cultured overnight. Using LB media diffusion agar technique wells of $1 \mathrm{~cm}$ diameter were made on nutrient agar plates. Using a micropipette, $100 \mu \mathrm{L}$ of nanoparticle suspension solution was poured onto each well on all plates. After incubation at $37^{\circ} \mathrm{C}$ for $24 \mathrm{~h}$, the diameter of inhibition zone was measured and recorded in millimeter.

Testing the antimicrobial activity using $\mathrm{Cp}-\mathrm{Ti}$, Ti-Ni alloys: In the present investigation, $100 \mu \mathrm{L}$ of nanoparticle solution was
Table 3: The chemical composition of the matrix, dark and grey phases of $\mathrm{Ti}-\mathrm{Ni}$ alloy.

\begin{tabular}{|l|l|l|}
\hline Element & Ti (at.\%) & Ni (at.\%) \\
\hline Phases & & \\
\hline Gray phase & 63.93 & 36.07 \\
\hline Dark phase & 64.18 & 35.82 \\
\hline Matrix & 51.91 & 48.09 \\
\hline
\end{tabular}

Table 4: The chemical composition of the investigated Cp-Ti (wt.\%).

\begin{tabular}{|l|l|l|l|l|l|l|l|}
\hline Al & Fe & Mo & Ni & Si & Sn & V & Ti \\
\hline 0.0014 & 0.088 & 0.004 & 0.008 & 0.0053 & 0.0126 & 0.002 & 99.9 \\
\hline
\end{tabular}

poured onto each well on all plates containing gram positive and gram negative bacterial strains, after incubation at $37^{\circ} \mathrm{C}$ for $24 \mathrm{~h}$, the diameter of inhibition zone was measured and recorded in millimeter. The antimicrobial activity of the alloys was tested against Gram-negative bacteria (Escherichia coli). The bacteria strain was cultured (overnight at room temperature). Using LB media diffusion agar technique wells of $1 \mathrm{~cm}$ diameter were made on nutrient agar plates. The two Ti alloys (i.e. $\mathrm{Cp}$-Ti and $\mathrm{Ti}-\mathrm{Ni}$ ) were poured onto each well on all plates. After incubation at $37^{\circ} \mathrm{C}$ for $24 \mathrm{~h}$, the diameter of inhibition zone was measured and recorded in millimeter.

\section{Characterization}

The crystalline structure, size and morphology of Ag-HA Nps and porous nanorods were examined by X-ray powder diffraction (XRD; PAN alytical X'Pert PRO MRD XL), Transmission electron microscopy and electron diffraction (TEM; JOEL 1230). The microstructure properties of the metal alloys surface were investigated using scanning electron microscopy (SEM; JEOL JSM 5410 LVSEM), also Microhardness (HMV-2E 344-04109-22) and corrosion rate of both Ti alloys were examined.

\section{Results}

\section{Microstructure investigation}

Scanning electron microscopy (SEM): Figure 1a displays SEM microstructures of the as-cast Ti51Ni49 alloy. The majority of the structure is composed of martensite phase (B19') with austenite phase (B2) as minority and some precipitates of $\mathrm{Ti}_{2} \mathrm{Ni}$. The dark phase in the microstructure is mainly located at the grain boundaries of the matrix, while the grey precipitated particles are essentially distributed inside the matrix.

The chemical composition of the matrix, dark and grey phases are given in table 3 the data given in table 4 are the averages that taken of at least five tests for each area with errors. Figure $1 \mathrm{~b}$ displays the microstructure consists mainly of equiaxed prior $\beta$ grains and a variety of $\alpha$-morphologies inside these grains. The $\alpha$-morphologies at different locations can be identified as (A) grain boundary $\alpha$, (B) fine acicular $\alpha$, and (C) Widmanstaetten $\alpha$.

Energy dispersive X-Ray (EDAX): Table 3 shows the chemical composition of the investigated $\mathrm{Cp}-\mathrm{Ti}$ (wt. \%). All measured element concentrations are within typical values of $\mathrm{Cp}$-titanium (grade 4) reported in the literature [17]. Figure 2 and the related table 3 show the EDAX analysis of the Cp-Ti specimen and it show that the ratio between titanium, oxygen, calcium, copper, and zinc as shown in the table. The chemical analysis carried out using energy dispersive X-ray (EDAX) spectroscopy figure 2 indicates Ti metal with oxygen, copper, zinc, and calcium. Atomic concentration values of approximately $49.17 \%$ for $\mathrm{Ti}$ and $30.2 \%$ for $\mathrm{O}$ as revealed by the EDAX spectrum and table 3 . This confirms that the chemical composition of $\mathrm{Cp}$ - $\mathrm{Ti}$ alloy reported in literature.

X-Ray diffraction (XRD) of Ti-Ni alloy: The XRD pattern of the as-cast Ti51Ni49 alloys in figure 2 shows the characteristic peaks of the given specimen before coating and without laser treatment, it could 
be concluded that the matrix shown is B19' martensite in addition to existing of a small amount of retained austenite, where characteristic of B2 was observed at $20=78^{\circ}$, and characteristic of B19' were observed at $20=42^{\circ}, 62^{\circ}$, and finally characteristic of $\mathrm{Ti}_{2} \mathrm{Ni}$ was observed at $2 \theta=45^{\circ}$.

Electrophoresis deposition of nanocrystalline silver hydroxyapatite (Ag doped HAP) on titanium

Transmission electron microscopy (TEM) analysis of (Ag-HA):
In order to understand the formation mechanism of the silver doped hydroxyapatite $\left[\mathrm{Ca}_{10}\left(\mathrm{PO}_{4}\right)_{6}(\mathrm{OH})-\mathrm{Ag}\right]$ nanoparticles, the experiments were carried out at room temperature $37^{\circ} \mathrm{C}$ which nanoparticles were collected from the reaction mixture. At the beginning of the reaction, $\mathrm{Ca}_{3}\left(\mathrm{PO}_{4}\right)_{2}$ were added to sodium silicate in the presence of SBF, producing hydroxyapatite particles (Eq. 1). $\mathrm{Ag}^{+}$ions are reduced by sodium borohydride $\left(\mathrm{NaBH}_{4}\right)$ to $\mathrm{Ag}^{0}$ (Eq. 2), which react with $\mathrm{Ca}_{10}\left(\mathrm{PO}_{4}\right)_{6}(\mathrm{OH})_{2}$ to replace one hydroxyl group $(\mathrm{OH})$ - producing

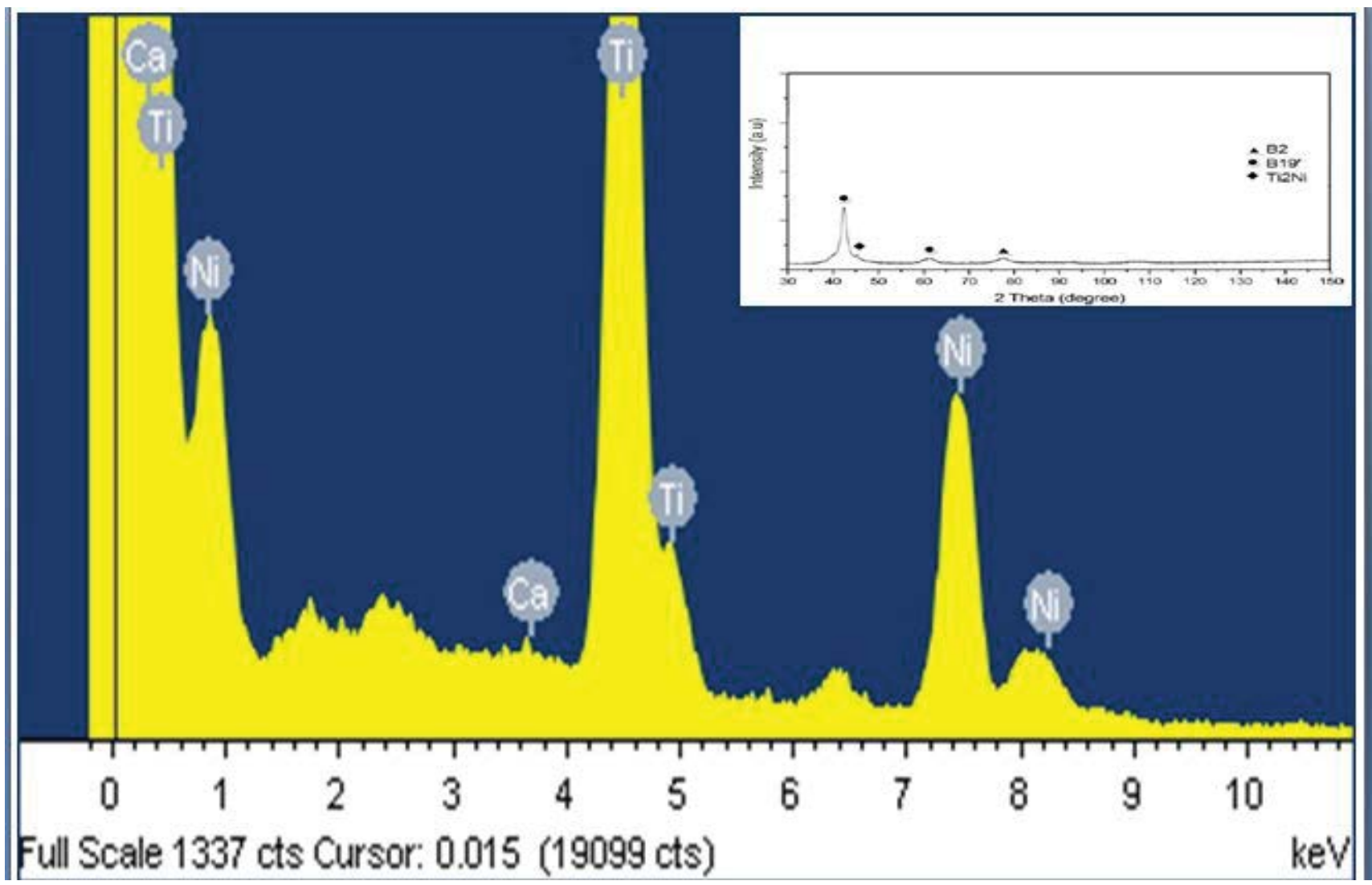

Figure 2: EDX patterns of Ti-Ni sample including the XRD patterns of Ti-Ni sample.

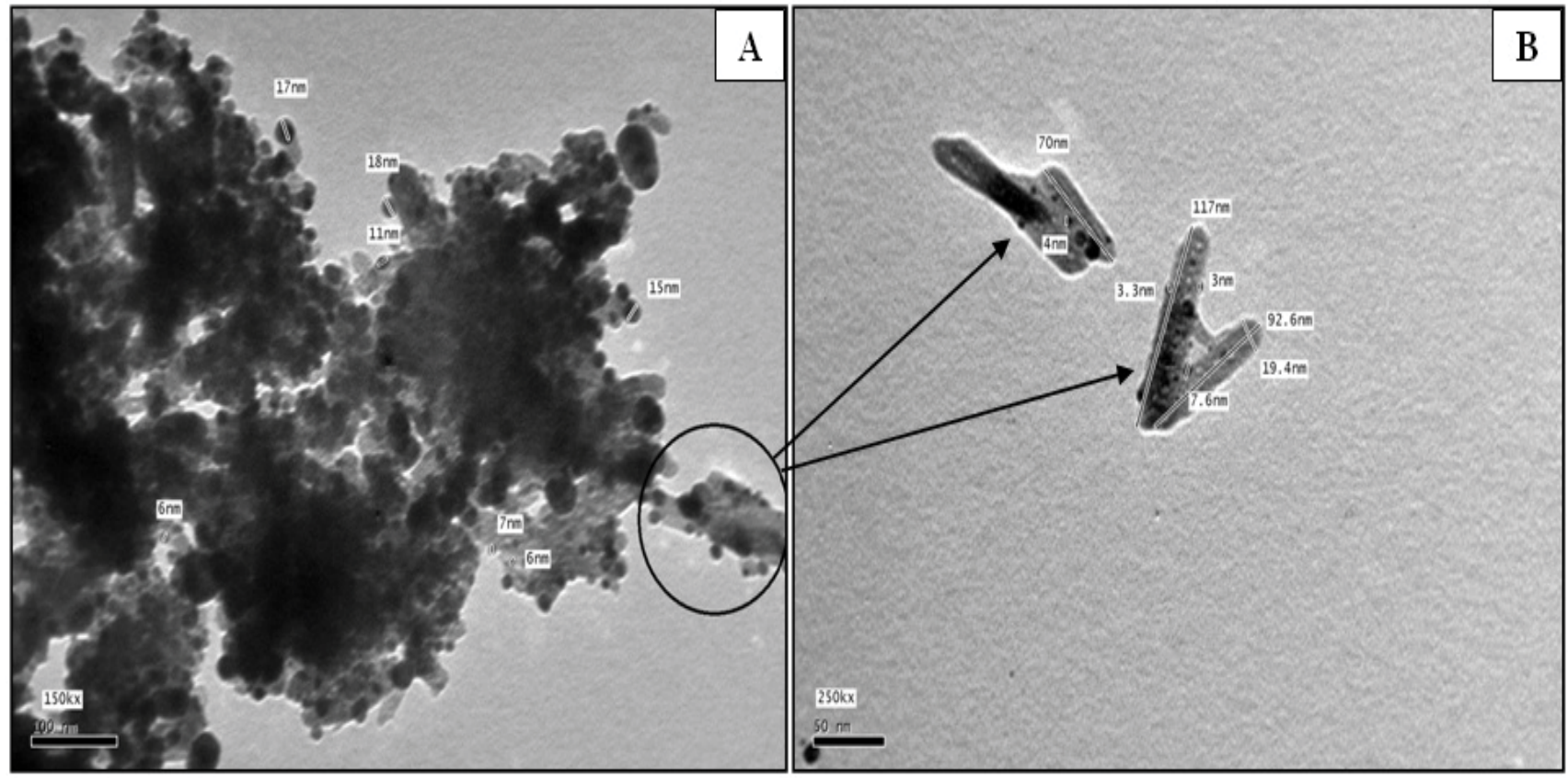

Figure 3: (A) TEM of Ag-HA nanoparticles at $100 \mathrm{~nm}$; (B) HA rod-like nanostructure doped silver with dimensions at $50 \mathrm{~nm}$. 
silver hydroxyapatite nanoparticles (Eq. 3).

$$
\begin{aligned}
& 3 \mathrm{Ca}_{3}\left(\mathrm{PO}_{4}\right)_{2}+\mathrm{Na}_{2} \mathrm{SiO}_{3} \stackrel{\mathrm{SBF}}{\longrightarrow} \mathrm{Ca}_{10}\left(\mathrm{PO}_{4}\right)_{6}(\mathrm{OH})_{2}(1), \\
& \mathrm{Ag}^{+}+\mathrm{NO}_{3}+\mathrm{NaBH}_{4} \longrightarrow \mathrm{Ag}^{0}(2), \\
& \mathrm{Ca}_{10}\left(\mathrm{PO}_{4}\right)_{6}(\mathrm{OH})_{2}+\mathrm{Ag}^{0} \longrightarrow \mathrm{Ca}_{10}\left(\mathrm{PO}_{4}\right)_{6}(\mathrm{OH})-\mathrm{Ag}(3),
\end{aligned}
$$

The size and morphology of the as-synthesized silver hydroxyapatite nanoparticles were further examined by TEM shown in figure 3A TEM images of the nanoparticles, while figure 3B shows that a focused HA nanoparticles which possesses a mostly rod-like structure with a shape 70-117 $\mathrm{nm}$ in length and $19.4 \mathrm{~nm}$ in diameter, with silver nanoparticles appear to be close to a spherical shape with 3.3-7.6 $\mathrm{nm}$ in diameter. This image indicates that the applied method for loading silver nano particles on calcium hydroxyapatite substrate were efficient procedure.
X-Ray diffraction (XRD) analysis of (Ag-HA): Figure 4 shows the characteristic peaks of the as-synthesized Ag-HA nanoparticles prepared at $37^{\circ} \mathrm{C}$. It shows the corresponding X-ray diffraction patterns for the previously synthesized Ag-HA nanoparticles at $\mathrm{pH}$ 7.4. characteristic of HA were observed at $20=25.9^{\circ}, 28.9^{\circ}, 34^{\circ}, 39.7^{\circ}, 46.5^{\circ}, 47.9^{\circ}$ and $49.5^{\circ}$, the intensive peaks were observed at $20=31.8^{\circ}, 32.18^{\circ}$, and $32.8^{\circ}$. Important peaks of Ag were observed at $20=38.2^{\circ}$, and $44^{\circ}$.

Selected area electron diffraction (SAED) analysis of (Ag-HA): The SAED patterns including in figure 4 show that, the diffraction spots are superimposed on the rings indicating the polycrystalline structure of the synthesized Ag-HA.

\section{Effect of processing parameters on deposition}

Influence of deposition time: For a fixed voltage, when increasing

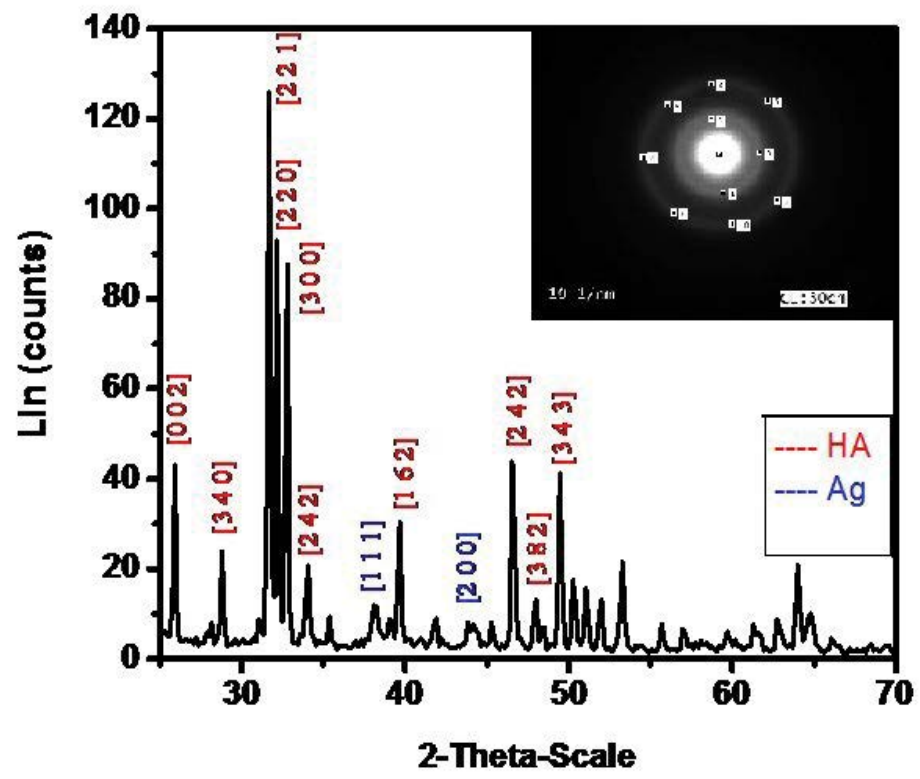

Figure 4: XRD patterns of Ag-HA nanoparticles including the SAED patterns of Ag-HA nanoparticles.
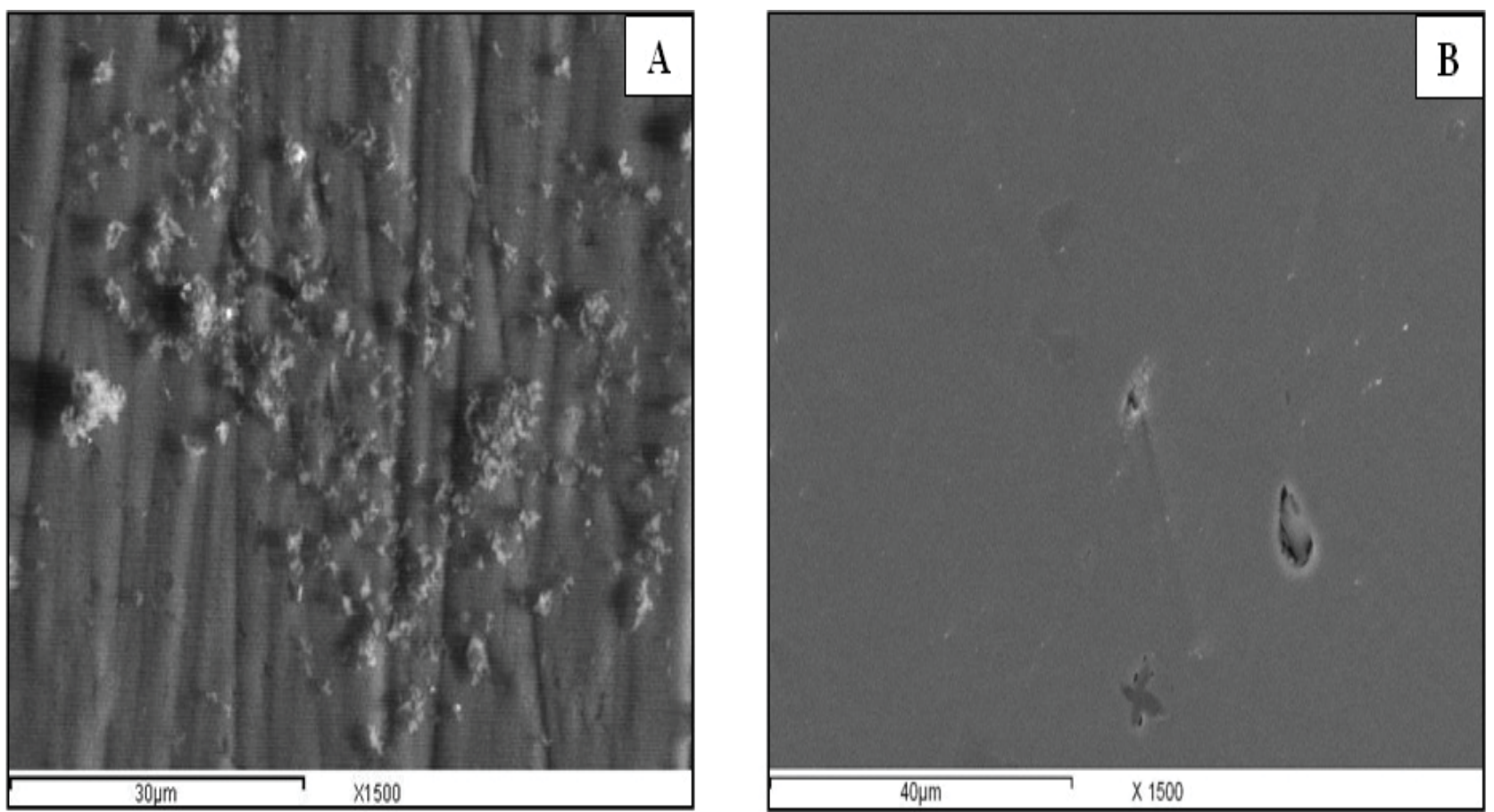

Figure 5: SEM of the Cp-Ti samples with various deposition time at fixed electric field (A) $30 \mathrm{~min}$; (B) $20 \mathrm{~min}$. 

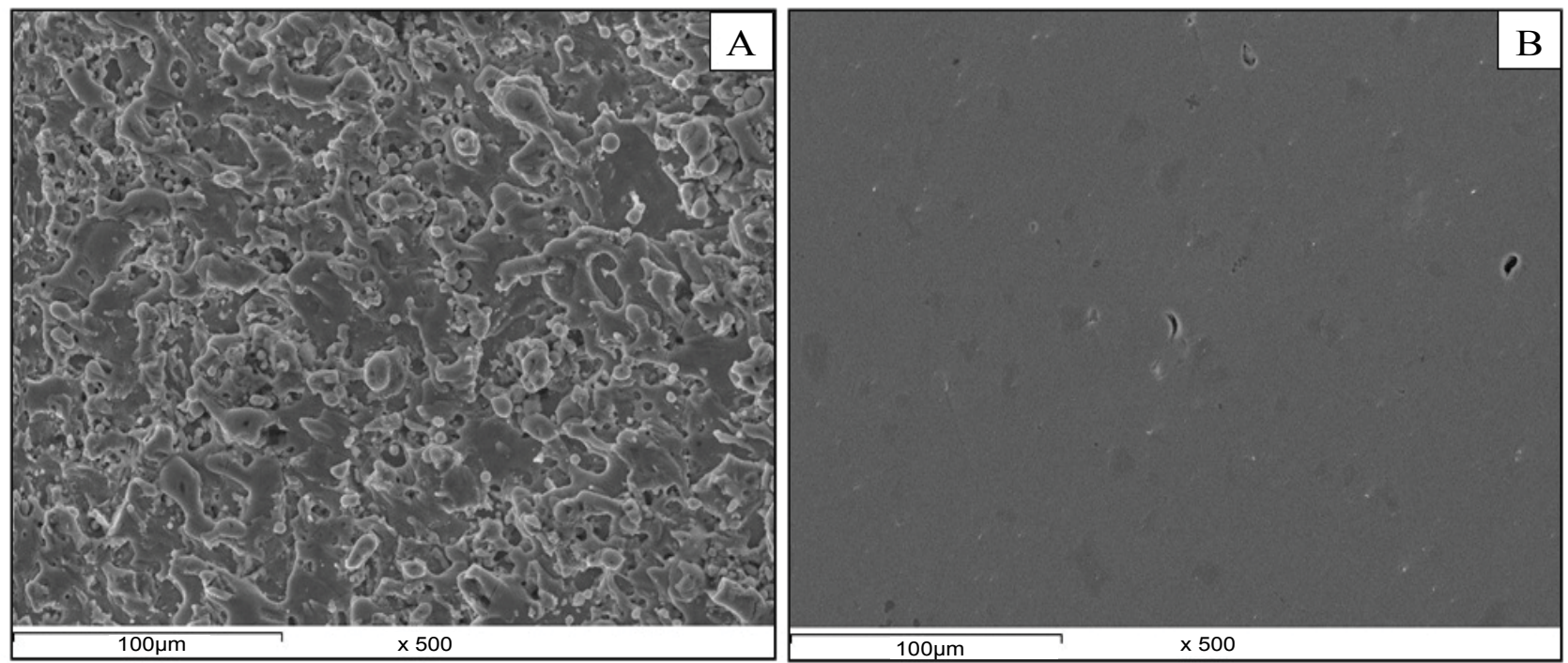

Figure 6: SEM of the Ti-Ni samples with various concentrations of Ag-HA nanoparticles at fixed Voltage (A) $0.5 \mathrm{gm} @ 150 \mathrm{ml}$; (B) 2 gm @150 ml.

Table 5: EDAX analysis of the Ti-Ni specimen.

\begin{tabular}{|l|l|l|}
\hline Element & Weight \% & Atomic \% \\
\hline C K & 81.1 & 95.05 \\
\hline Si K & 0.09 & 0.04 \\
\hline S K & 0.12 & 0.05 \\
\hline Ca K & 0.09 & 0.03 \\
\hline Ti K & 8.33 & 2.45 \\
\hline Fe K & 0.43 & 0.11 \\
\hline Ni K & 7.54 & 1.81 \\
\hline Cu K & 1.98 & 0.44 \\
\hline Ag M & 0.32 & 0.02 \\
\hline Totals & 100 & \\
\hline
\end{tabular}

the deposition time the deposition rate decreases as well. In our experiment the deposition time was adjusted first at 10 minutes then increased to 20 minutes and finally 30 minutes. From the figure $5 \mathrm{~A}$, it is observed that $\mathrm{Ag}-\mathrm{HA}$ is deposited with good coverage over the entire metal surface at 30 minutes. While figure $5 \mathrm{~B}$ shows the crystals of Ag-HA at 20 minutes which look like aggregations on the surface. Then we can conclude that the growth of Ag-HA nanocrystals occurs with greater deposition times and the crystals cover up maximum area on the implant surface leaving very small holes and finer coating at lower deposition times.

Influence of concentration of nanoparticles in the electrolyte: When the concentration of the solids is high, they deposit at an equal rate. However, when the volume fraction of the nanoparticles is low the particles deposit at rate proportional to their individual electrophoresis mobility. At fixed parameters: voltage $(30 \mathrm{~V})$ and deposition time (20 min) figure 6A shows the crystals of Ag-HA with concentration $0.5 \mathrm{gm}$ of the nanoparticles at $150 \mathrm{ml}$ of the electrolyte, while figure $6 \mathrm{~B}$ shows the crystals of Ag-HA with concentration $2 \mathrm{gm}$ of the nanoparticles. The coating thus formed on the samples in figure $6 \mathrm{~A}$ is quite non-uniform, but it is observed from figure $6 \mathrm{~B}$ that $\mathrm{Ag}$ HA is deposited in a form with good coverage over the entire surface. The growth of the HA crystals is more pronounced in the 2 gm sample as compared to the $0.5 \mathrm{gm}$ sample, which leads to better coating on the surface as observed from the figures. This better coverage of the coating in the $2 \mathrm{gm}$ treated sample is due to the fact that a proper growth of the HA crystals has taken place with more concentration, which also results in giving a good thick uniform layer on the metal surface.

\section{Characteristics of the Ag-HA coating on Ti alloys}

Energy dispersive X-Ray (EDAX): Figure 7A and the related
Table 6: EDAX analysis of the $\mathrm{Cp}$-Ti specimen.

\begin{tabular}{|l|l|l|l|l|l|}
\hline Element & App conc & Intensity corrn. & Weight \% & Weight \% sigma & Atomic \% \\
\hline C K & 28.87 & 0.5204 & 3.62 & 0.62 & 9.02 \\
\hline O K & 96.08 & 0.2338 & 26.82 & 1.6 & 50.17 \\
\hline Ca K & 4.07 & 1.1811 & 0.22 & 0.06 & 0.17 \\
\hline Ti K & 746.92 & 0.933 & 52.24 & 1.22 & 32.64 \\
\hline Cu K & 187.29 & 0.8513 & 14.36 & 0.45 & 6.76 \\
\hline Zn K & 35.24 & 0.8627 & 2.67 & 0.24 & 1.22 \\
\hline Ag M & 1.15 & 0.9505 & 0.08 & 0.15 & 0.02 \\
\hline Totals & & & 100 & & \\
\hline
\end{tabular}

table 5 shows the EDAX analysis of the Ti-Ni specimen and it shows that the ratio between titanium, oxygen, calcium, copper, zinc, carbon, and silver as shown in the table. The chemical analysis carried out using energy dispersive X-ray (EDAX) spectroscopy figure 7A indicates Ti metal with silver ions which indicate that the Ti specimen is coated with Ag-HA nanoparticles.

Figure $7 \mathrm{~B}$ and the related table 6 show EDAX analysis of the $\mathrm{Cp}$ Ti metal coated with silver ions, where the ratio between titanium, oxygen, calcium, copper, zinc, carbon, and silver as shown in the table indicate that the Ti specimen is coated with Ag-HA nanoparticles.

Scanning electron microscopy (SEM): Figure 8 show the scanning electron micrograph of Ag-HA nanocomposite coated on the Ti-Ni. It is observed that at constant parameters Ag-HA is deposited with good coverage over the entire metal surface of the three Ti alloys without any cracks on it. Also we can conclude that the microstructure of the coating is finer at the following conditions:

- Higher voltages $(30 \mathrm{~V})$ due to higher driving force at 30 volt compared to 20 volt.

- Deposition time $20 \mathrm{~min}$.

- Concentration of Ag-HA nanoparticles equal 2 gm @ $150 \mathrm{ml}$ of electrolyte.

\section{Effect of Nd:YAG laser on the Ti alloys}

Effect on the morphological structure: It was found that interaction of the Nd: YAG laser beam with the Ti alloys resulted a change in the morphological structure of the specimen. SEM images of the Ti-Ni alloy samples figure 9 showed that as the samples undergo $\mathrm{Nd}$ :YAG laser surface treatment, melting and re-solidification of the surface occurs. In this instance, it is clear from figure 9A and figure $9 \mathrm{~B}$ that the melting and solidification experienced by the Ti-Ni alloy occasioned the observed increase in surface roughness. 

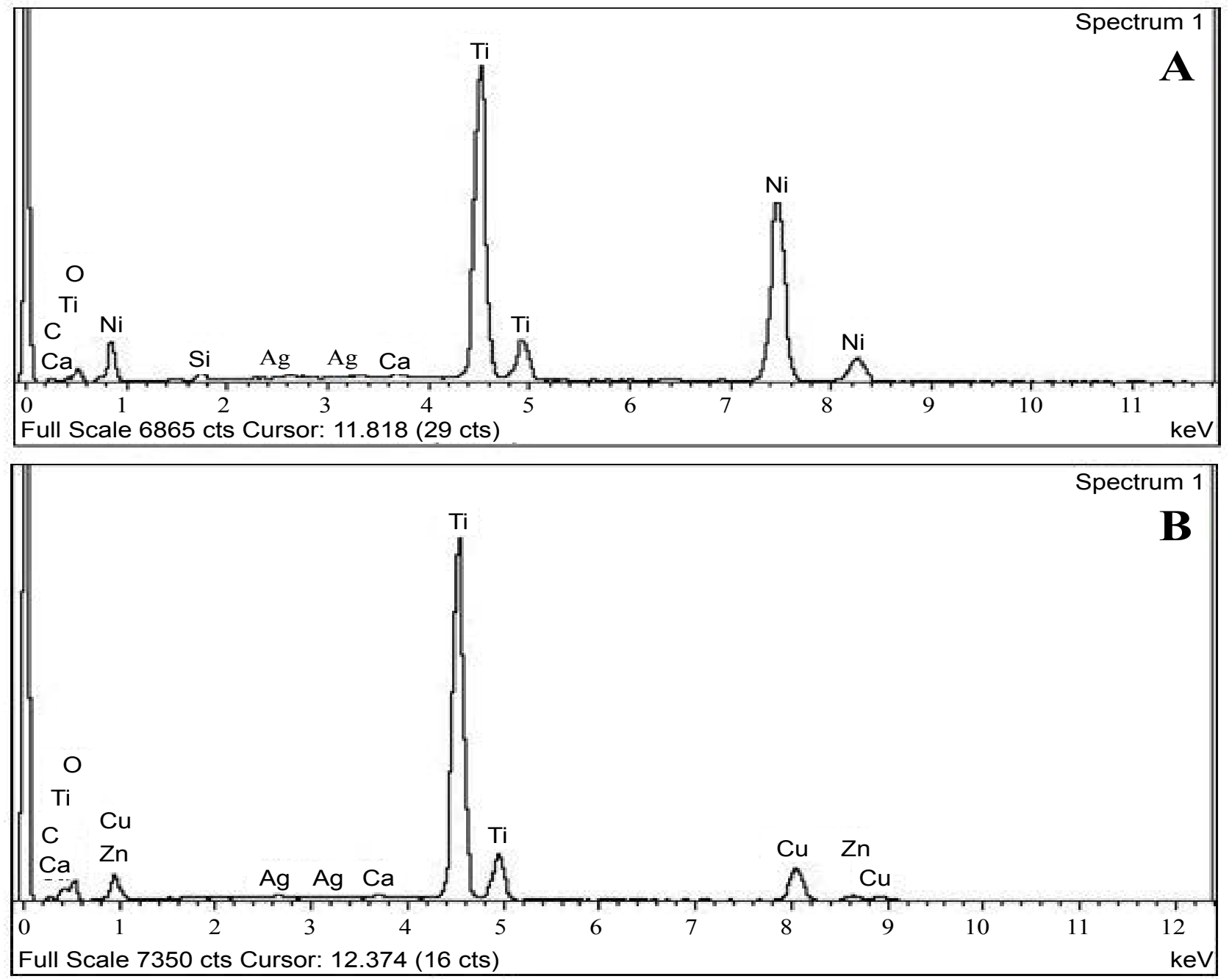

Figure 7: EDX patterns of (A) Ti-Ni; (B) Cp - Ti coated sample.

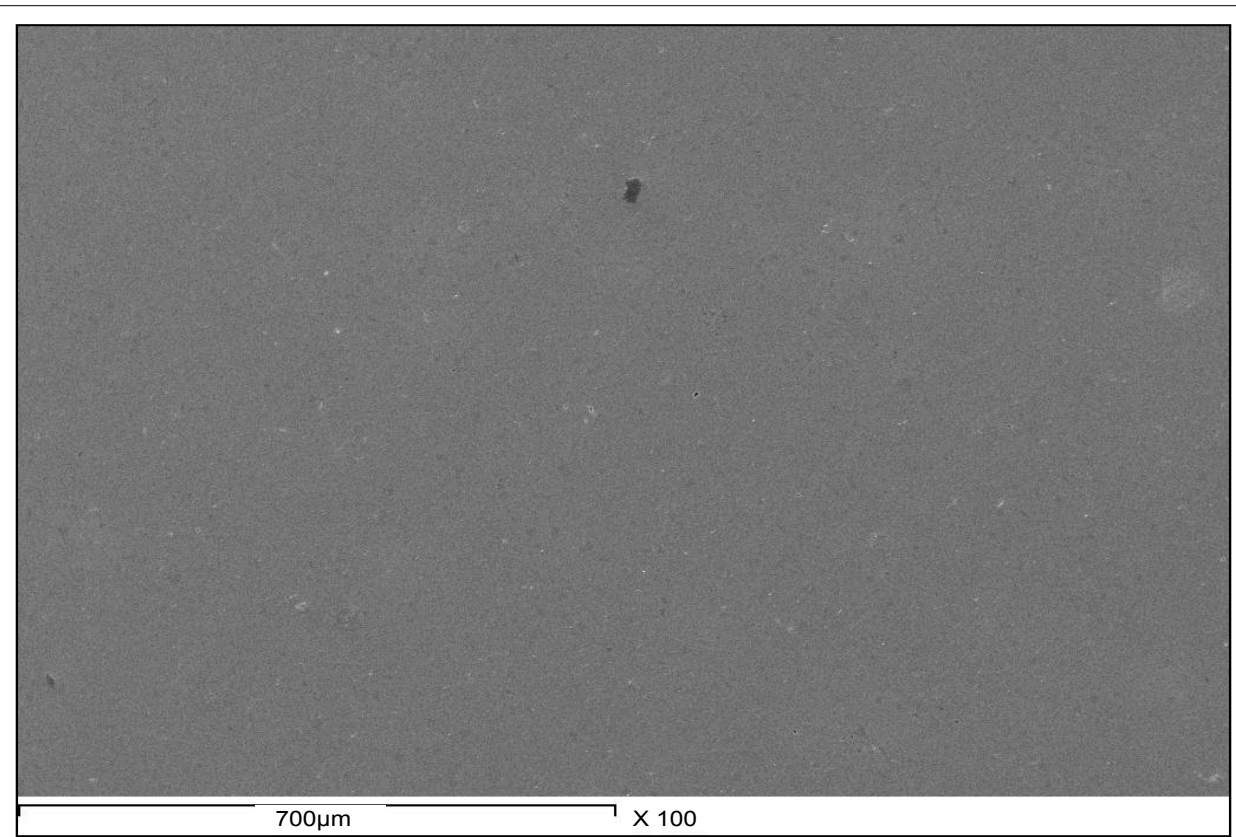

Figure 8: SEM of the coated Ti-Ni sample.

SEM images of the Cp-Ti alloy samples figure 10B indicate that the inclusions are disappeared and the scratches due to machining and polishing are sealed due to direct laser surface heating.
Effect on Ag-HA coated nanolayer: Figure 11A and figure 11B show SEM images of $\mathrm{Cp}$-Ti coated sample before and after laser treatment respectively. Where figure $11 \mathrm{~B}$ shows that laser treatment 

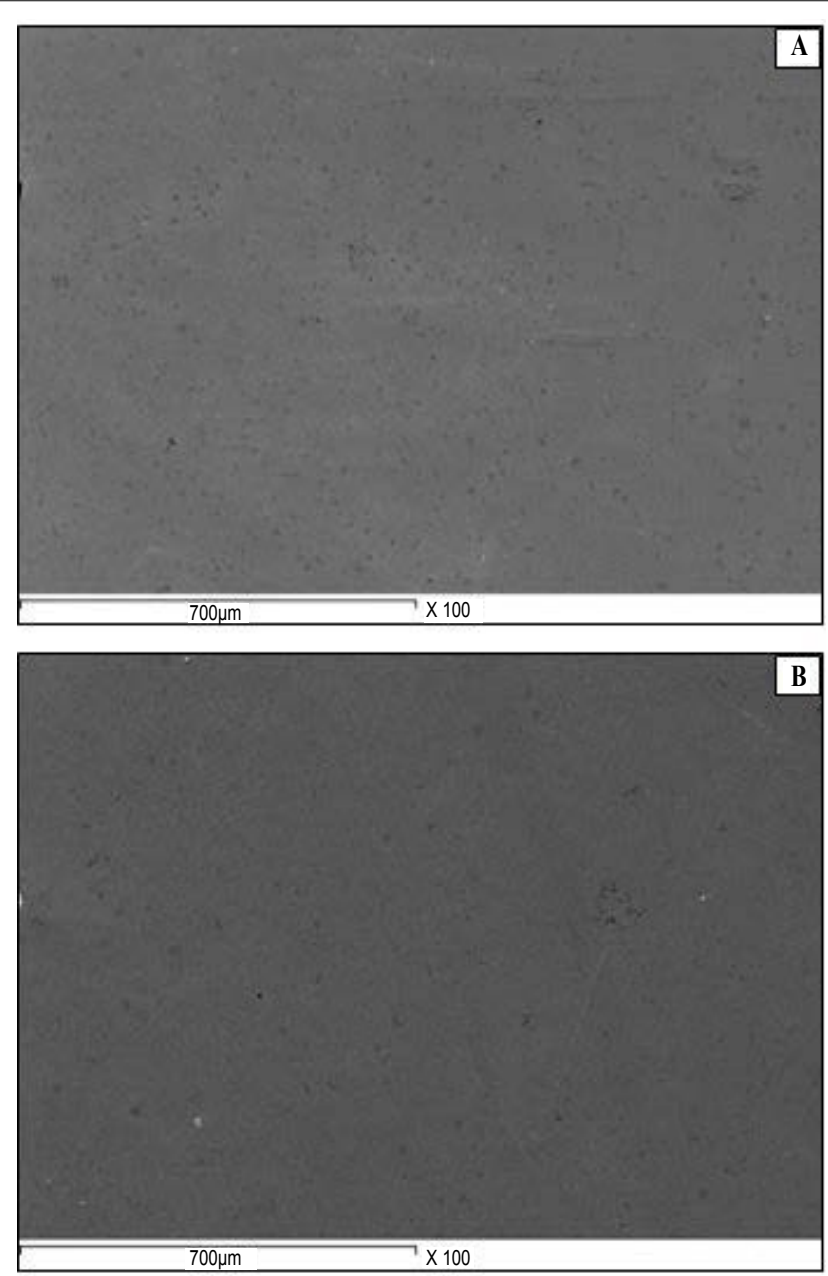

Figure 9: SEM of Ti-Ni specimen (A) before laser treatment; $(B)$ after laser treatment.

resulted in more homogeneous Ag-HA layers as donated by the give arrows. Figure 12A and figure 12B show SEM images of Ti-Ni coated sample before and after laser treatment respectively.

Effect on microstructure of the alloy: Figure 13A shows the microstructures of $\mathrm{Ti}-\mathrm{Ni}$ alloys before laser treatment, and figure $13 \mathrm{~B}$ shows the microstructure of the same alloy after laser treatment $\mathrm{Nd}: Y A G$ at wavelength $1064 \mathrm{~nm}$. It was obvious that Nd:YAG 1064 $\mathrm{nm}$ laser beam causes the formation of a continuous and defect-free alloyed zone as in figure 13B. The dark phase in the microstructure is mainly located at the grain boundaries of the matrix, while the grey precipitated particles are essentially distributed inside the matrix.

\section{Mechanical characterization of the Ti alloys}

Microhardness: The Microhardness measurement gives a good indication about the mechanical properties of the given alloy. The effects of Ag-HA coating and surface laser treatment on the final mechanical properties of extruded $\mathrm{Cp}-\mathrm{Ti}$, and $\mathrm{Ti}-\mathrm{Ni}$ alloys respectively were investigated in figure $14 \mathrm{~A}$ and figure $14 \mathrm{~B}$. We can observe that the microhardness values of specimens coated with $\mathrm{Ag}$ HA nanoparticles were higher than those without coated, and the values of specimens treated with Nd:YAG were higher than both coated and uncoated specimens. For Cp-Ti alloy figure 14A the microhardness value was $460 \mathrm{HV}$ for the reference specimen, 880 $\mathrm{HV}$ for the coated and then surface laser treatment, and $1034 \mathrm{HV}$ for uncoated, but for Ti-Ni sample the microhardness value was $247 \mathrm{HV}$ for the reference specimen, $354 \mathrm{HV}$ for the coated and then surface laser treatment, and $514 \mathrm{HV}$ for uncoated.

Corrosion: The barrier effect of the corrosion of Ti metal in a
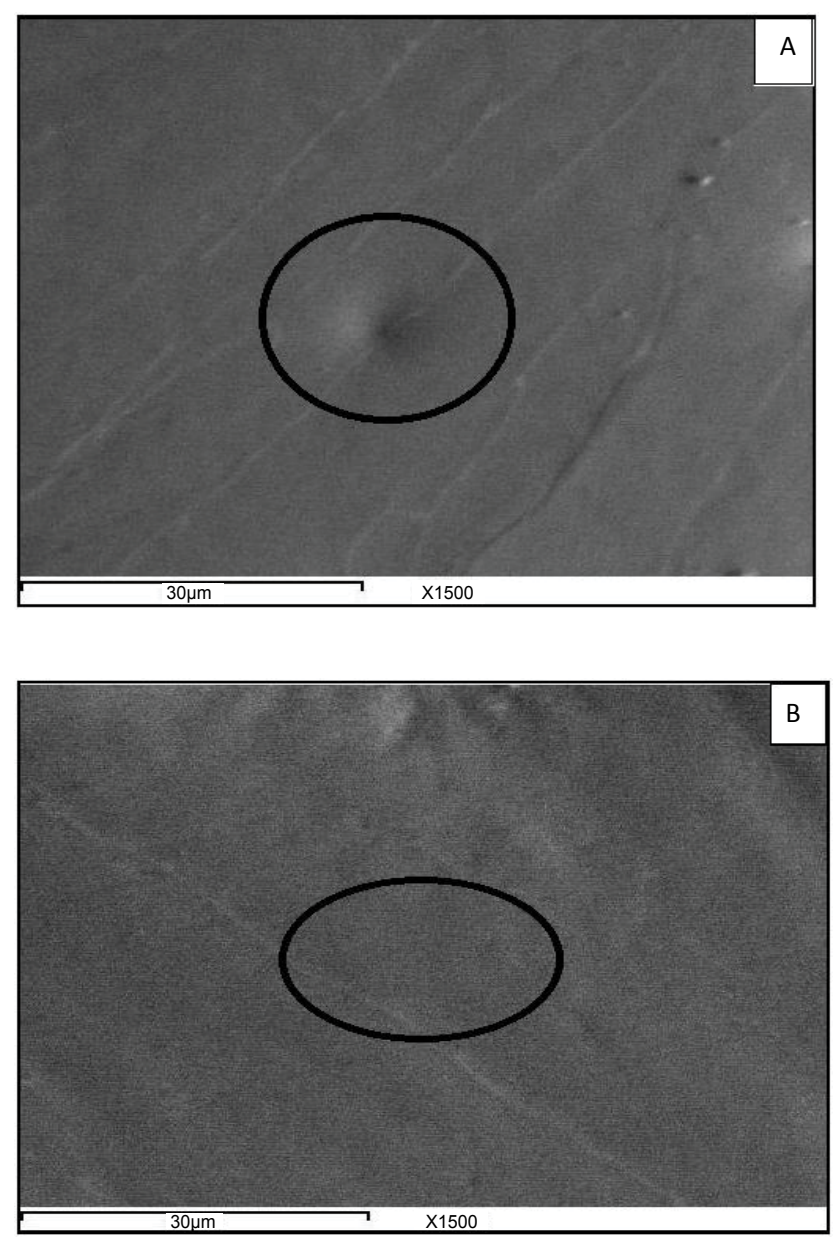

Figure 10: SEM of Cp-Ti specimen (A) before laser treatment; (B) after laser treatment.
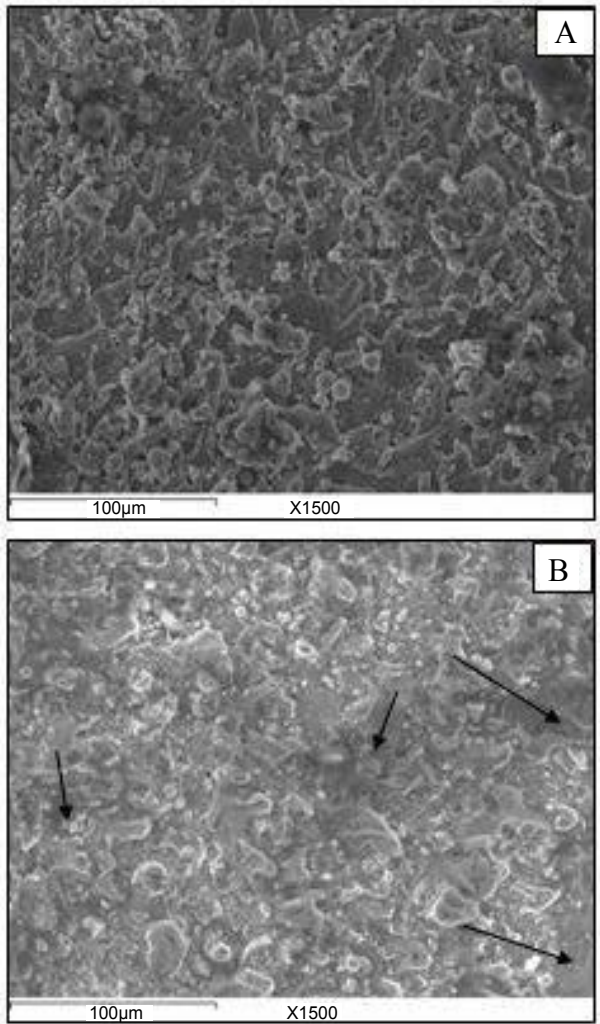

Figure 11: SEM of the coated Cp-Ti specimen (A) before laser treatment; $(B)$ after laser treatment. 


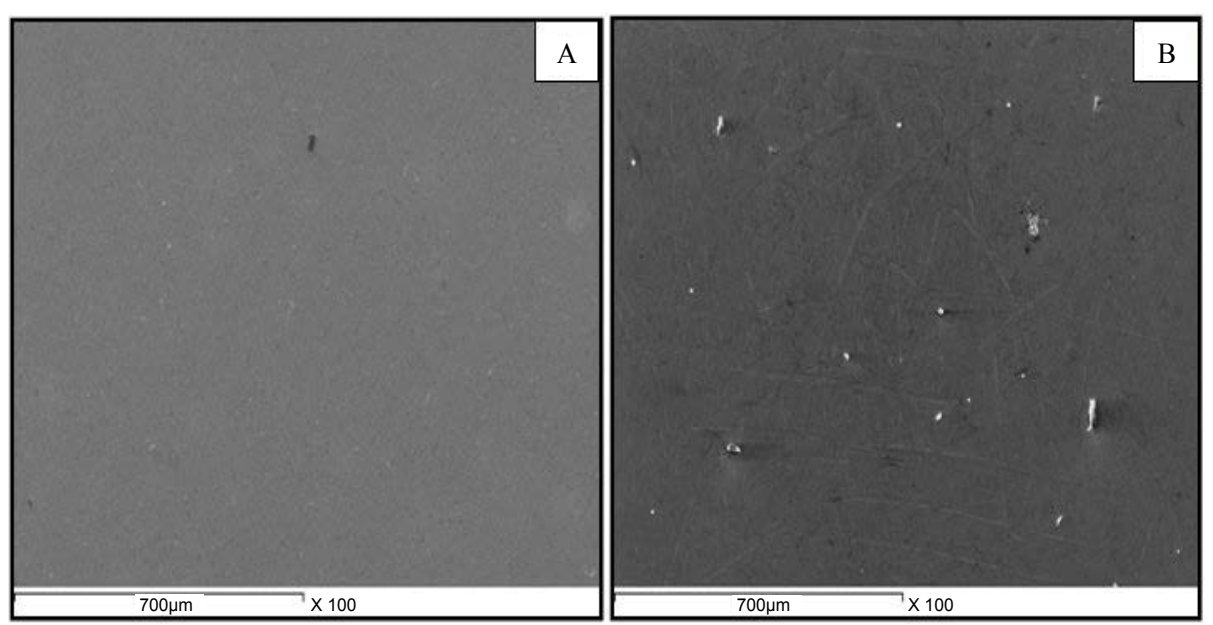

Figure 12: SEM of the coated Ti-Ni specimen (A) before laser treatment; $(B)$ after laser treatment.
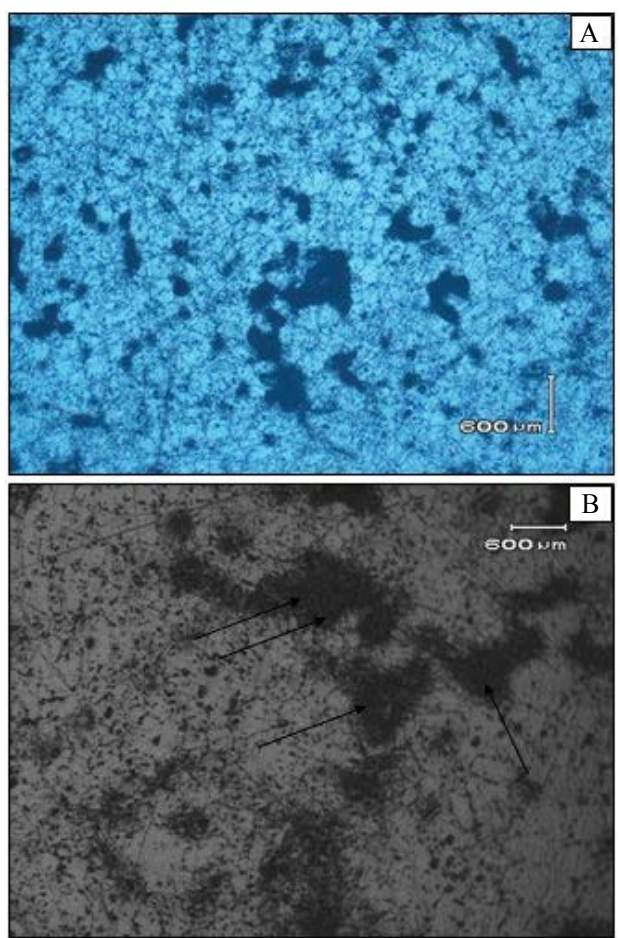

Figure 13: Microstructure of Ti-Ni specimen (A) before laser treatment; (B) after laser treatment $1064 \mathrm{~nm}$.
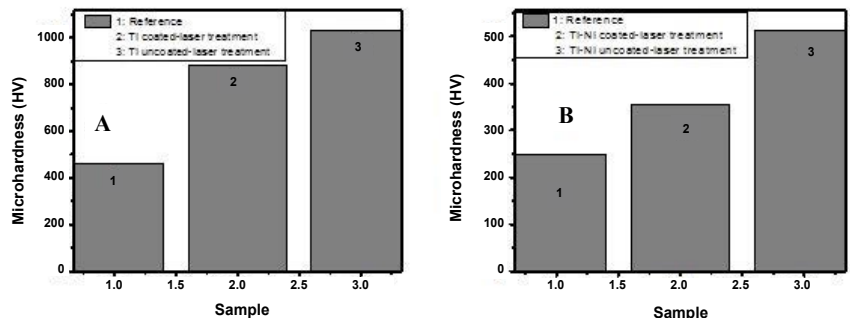

Figure 14: Microhardness profile of (A) $\mathrm{Cp}-\mathrm{Ti}$; (B) Ti-Ni alloys.

given environment depends on the characteristics and properties of the nanolayer coating produced. Thickness, uniformity, and adherence will condition the corrosion rate and morphology of attack to the metal surface.

Figure 15 shows the corrosion rate of alloys first after surface coating, then after laser treatment of the surface. Before $72 \mathrm{~h}$

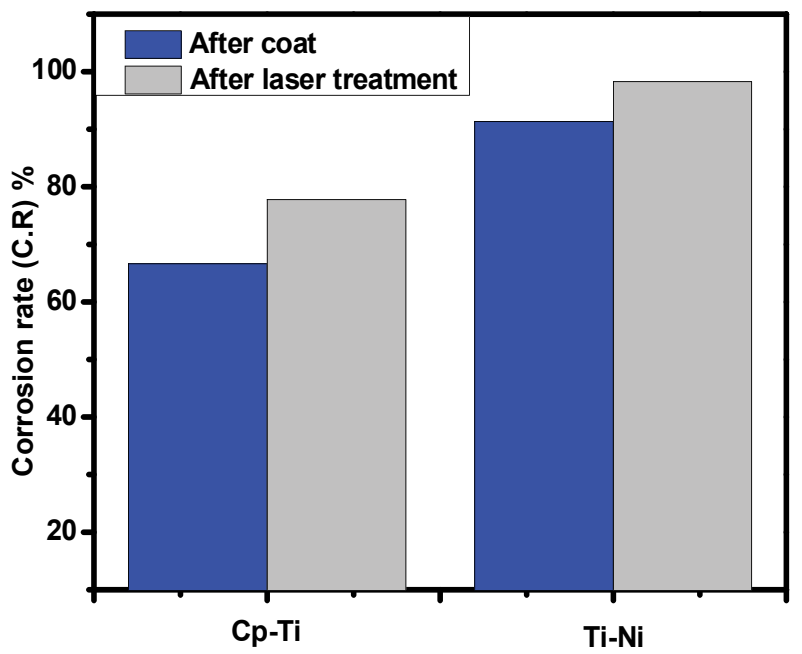

Figure 15: Corrosion profile of $\mathrm{Cp}-\mathrm{Ti}$ and $\mathrm{Ti}-\mathrm{Ni}$ alloys.

immersion in SBF, the corrosion rate of every alloy decreased when exposure to laser irradiation, and exceeds the corrosion resistance value after surface coating, where Ti-Ni alloy achieving the maximum value in both cases. It can be observed that the corrosion resistance of the four Ti alloys increased with laser surface treatment.

\section{The antimicrobial activity of Ag-HA nanoparticles}

The bactericidal activity results showed that HA-Ag nanoparticles are strongly active against the gram negative, and gram positive bacteria strains, therefore it can be considered as an antimicrobial biomaterial. The bacterial concentration in the experiments exceeded that encountered by biomaterials at surgical sites. Thus, the bactericidal ability of the as-prepared coatings could satisfy the requirement of clinical applications. In this respect when relatively larger Ag nanoparticles were used, the concentration of the released $\mathrm{Ag}^{+}$ions was lower sustaining size dependent bactericidal activity $[18,19]$. Smaller nanoparticles have larger surface area and have greater antibacterial effect. Figure 16 shows the microbial inhibition zone of the tested components, that pseudomonas aeruginosa has the highest inhibition zone $(24 \mathrm{~mm})$ among the gram negative bacteria, followed by Escherichia coli $(17 \mathrm{~mm})$. For gram positive bacteria bacillus cereus $(16 \mathrm{~mm})$ followed by micrococcus luteus (13 $\mathrm{mm})$. It has been reported in the literature that with $0.01 \mathrm{mmol} / \mathrm{mL}$ concentration of silver nanoparticles $23 \mathrm{~mm}$ clear inhibition zone appeared for both Escherichia coli and pseudomonas aeruginosa [20]. Table 7 shows Microbial activity conditions of Ti alloys using Escherichia coli, where Ti-Ni showed the highest inhibition zone 25 


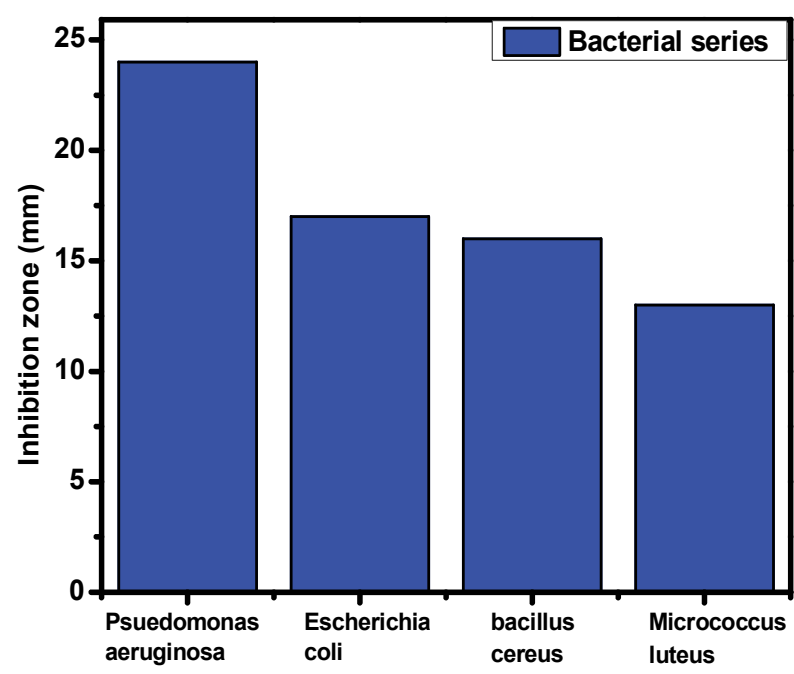

Figure 16: Size of the inhibition zone for Ag-HA nanoparticles against the tested microorganisms.

Table 7: Microbial activity conditions of Ti alloys using Escherichia coli.

Microbial activity of Ti alloys using Escherichia coli

\begin{tabular}{|l|l|l|l|}
\hline Sample & Incubation time $(\mathrm{hr})$. & Temperature $\left({ }^{\circ} \mathrm{C}\right)$ & Inhibition zone $(\mathrm{mm})$ \\
\hline 1. $\mathrm{Ti}-\mathrm{Ni}$ & $24 \mathrm{hr}$. & $37^{\circ} \mathrm{C}$ & $25 \mathrm{~mm}$ \\
\hline 2. $\mathrm{Cp}-\mathrm{Ti}$ & $24 \mathrm{hr}$. & $37^{\circ} \mathrm{C}$ & $25 \mathrm{~mm}$ \\
\hline
\end{tabular}

$\mathrm{mm}$, and $\mathrm{Cp}-\mathrm{Ti} 22 \mathrm{~mm}$. Moreover, to compare the microbial activity of both alloys (Ti-Ni and $\mathrm{Cp}-\mathrm{Ti}$ ), the alloys were tested on the same bacterial strain (Escherichia coli). The experiments were performed on titanium alloys coated with Ag-HA nanoparticles. Results presented in table 7 indicate that $\mathrm{Ti}-\mathrm{Ni}$ alloy showed the highest inhibition zone $25 \mathrm{~mm}$, and Cp-Ti $22 \mathrm{~mm}$. These results are in agreement with $\mathrm{Lu}$, et al. [21], where the antibacterial and cell culture tests were used to evaluate the antibacterial properties and biocompatibility of HA/Ag composite coatings, respectively. The results indicated the as-prepared coatings had good antibacterial properties and biocompatibility. In this regard, the in vitro bacterial adhesion study of Zheng, et al [22], indicated a significantly reduced number of bacteria (S. aureus, $\mathrm{S}$. epidermidis and $\mathrm{P}$. gingivalis) on the $\mathrm{Ti}-\mathrm{Ni}-\mathrm{Ag}$ alloy plate surface when compared with that on $\mathrm{Ti}-\mathrm{Ni}$ alloy plate surface. Also, results of Kazemzadeh-Narbat, et al. [23] demonstrated that CaP-Tet213 was a more efficient antimicrobial coating than CaP-MX226, CaP-hLF1-11 or CaP-tobramycin following incubation of $\mathrm{CaP}$ implants with equimolar concentrations of Tet213, the commercially developed antimicrobial peptide MX-226, hLF1-11 or tobramycin.

\section{Conclusion}

This paper has identified $\mathrm{Cp}-\mathrm{Ti}$ and $\mathrm{Ti}-\mathrm{Ni}$ alloys as a promising candidate biomaterials for mechanical component applications. Ti alloys, when appropriately processed and fabricated, is dimensionally stable and hard. The mechanical properties as corrosion and microhardness with respect to dental, orthopedic and cardiovascular implants faces lots of challenges as there are still a number of problems to be solved. The corrosion resistant variations and nontoxicity of surface coated and laser treated Ti-based metal alloys have been thoroughly evaluated. The Ag- $\mathrm{HA}$ and $\mathrm{Ti}$ alloys $\mathrm{Cp}-\mathrm{Ti}$ and $\mathrm{Ti}-$ Ni have bactericidal activity and could be considered as antimicrobial biomaterial that could be used for medical applications.

\section{Acknowledgement}

We thank all our colleagues in the Laser Unit, and the financial support of the National Research Center, Egypt.

\section{References}

1. Ikeda M, Ueda M, Narita M, Suzuki A (2003) The influence of cooling rate from a temperature within beta single phase region. CAMP-ISIJ 16: 613.

2. Soma T, Niinomi M, Akahori T, Ikeda M, Suzuki A, et al. (2003) Fatigue properties and microstructure of low cost b-titanium alloys for health care applications, Proceedings of the Annual Meeting of Japan Light Metal Institute. 81.

3. Mitsuo Niinomi (2003) Recent research and development in titanium alloys for biomedical applications and healthcare goods. Science and Technology of Advanced Materials 4: 445-454.

4. Dr. Joe Blaes (2007) Pearls for your Practice column, Footings to Finishes, "Finishes" "Practice".

5. JiaPing Li (2007) Porous titanium for biomedical applications: Development characterization and biological evaluation. University of Twente, Enschede, The Netherlands.

6. Branemark PI, Adell R, Breine U, Hansson BO, Lindström J, et al. (1969) Intra-osseous anchorage of dental prostheses. I. Experimental studies. Scand J Plast Reconstr Surg 3: 81-100.

7. Hanawa T, Ota M (1991) Calcium phosphate naturally formed on titanium in electrolyte solution. Biomaterials 12: 767-774.

8. Kasemo B, Lausmaa J (1991) The biomaterial-tissue interface and its analogues in surface science and technology. In: Davies JE The bonebiomaterial interface. (edn) University of Toronto press, Toronto, 19-32.

9. Hildebrand HF, Hornez JC (1998) Biological response and biocompatibility In: Helsen JA, Breme HJ Metals as biomaterials. (edn) John Wiley \& Sons Ltd, Chichester, 265-290.

10. HENCH L L (1991) Bioceramics: from concept to clinic. J Am Ceram Soc 74 $1487-1510$

11. SADJADI MS, EBRAHIMI AFARANI HR, ZARE K (2010) 22: 641-645.

12. Khaled M Ibrahim, Mansour Mhaede, Lothar Wagner (2012) Effect of Annealing Temperature on Microstructure and Mechanical Properties of Hot Swaged cp-Ti Produced by Investment Casting. JMEPEG 21: 114-118.

13. Ibrahim Kh M, Elbagoury N, Fouad $Y$ (2011) Microstructure and martensitic transformation of cast TiNiSi shape memory alloys, Journal of Alloys and Compounds 509: 3913-3916.

14. Bayraktar D, Tas AC (1999) J Eur Ceram Soc 19: 2573

15. Tas AC (2000) Synthesis of biomimetic Ca-hydroxyapatite powders at 37 degrees $C$ in synthetic body fluids. Biomaterials 21: 1429-1438.

16. Shaokang Guan, Junhua Hu, Liguo Wang, Shijie Zhu, Huanxin Wang, et al. (2011) Mg Alloys Development and Surface Modification for Biomedical Application. In: Frank Czerwinski Magnesium Alloys - Corrosion and Surface Treatments. InTech, Rijeka, Croatia, Europe, 109-152.

17. Bermingham M J, McDoland S D, Dargusch M S, John D H (2008) The Mechanism of Grain Refinement of Titanium by Silicon. Scripta Materialia 58: 1050-1053.

18. Panacek A, Kvitek L, Prucek R, Kolar M, Vecerova R, et al. (2006) Silver colloid nanoparticles: synthesis, characterization, and their antibacterial activity. J Phys Chem B 110: 16248-16253.

19. Lkhgvajav N, Yasa I, Celik E, Koizhaganova M, Sari O (2011) Digest J Nanomat Biostruct 6: 149

20. Ghassan Mohammad Sulaiman, Wasnaa Hatif Mohammed, Thorria Radam Marzoog, Ahmed Abdul Amir Al-Amiery, Abdul Amir H. Kadhum, et al. (2013) Green synthesis, antimicrobial and cytotoxic effects of silver nanoparticles using Eucalyptus chapmaniana leaves extract. Asian Pac J Trop Biomed 3: 58-63.

21. Xiong Lu, Bailin Zhang, Yingbo Wang, Xianli Zhou, Jie Weng, et al. (2011) Nano-Ag-loaded hydroxyapatite coatings on titanium surfaces by electrochemical deposition. J R Soc Interface 8: 529-539.

22. Zheng YF, Zhang BB, Wang BL, Wang YB, Li L, et al. (2011) Introduction of antibacterial function into biomedical TiNi shape memory alloy by the addition of element Ag. Acta Biomater 7: 2758-2767.

23. Kazemzadeh-Narbat M, Kindrachuk J, Duan K, Jenssen H, Hancock RE, et al. (2010) Antimicrobial peptides on calcium phosphate-coated titanium for the prevention of implant-associated infections. biomaterials 31: 9519-9526. 